\title{
Ocorrência e distribuição do gênero Caulerpa J.V. Lamour. (Bryopsidales - Chlorophyta) no Estado de Alagoas, Nordeste Brasileiro
}

\author{
Victor Andrei Rodrigues Carneiro, ${ }^{1,3}$, Maria de Fátima de Oliveira-Carvalho ${ }^{2}$, \\ Jhullyrson Osman Ferreira Brito ${ }^{1}$, Fillype Emannuel Gonçalves Quintella Lima ${ }^{1} \mathrm{e}$ \\ Élica Amara Cecília Guedes ${ }^{1}$
}

Recebido: 3 agosto 2018; aceito: 22 outubro 2019

Como citar: Carneiro, V.A.R., Oliveira-Carvalho, M.F., Brito, J.O.F., Lima, F.E.G.Q. \& Guedes, EA.C. 2019. Ocorrência e distribuição do gênero Caulerpa J.V.Lamour. (Bryopsidales - Chlorophyta) no Estado de Alagoas, Nordeste Brasileiro. Hoehnea 46: e712018. http://dx.doi.org/10.1590/2236-8906-71/2018.

ABSTRACT - (Occurrence and distribution of the genus Caulerpa J.V.Lamour. (Bryopsidales - Chlorophyta) in the State of Alagoas, Northeast Brazil). The genus Caulerpa is an important component of the phycological flora from the Brazilian Northeast Coast. The aim of the present research was to identify, describe and provide information about the distribution and ecology of the species of this genus at the coast of Alagoas State, contributing to the knowledge of the Brazilian phycological flora, which is poorly known in this regionThe specimens were collected from six beaches along the coast of Alagoas State. Caulerpa exsiccates deposited in the MAC Herbarium of the Environmental Institute of Alagoas were also analyzed. Fourteen infrageneric taxa were identified, distributed into in twelve species and three varieties, growing on rocky and sandy substrates. In this work, it is reported for the first time on the coast of Alagoas the occurrence of $C$. cupressoides var. flabellata, C. kempfii, C. mexicana, C. microphysa, C. verticillata and Caulerpa sp.

Keywords: Caulerpa, green algae, macroalgae, Northeastern Brazil, taxonomy.

RESUMO - (Ocorrência e distribuição do gênero Caulerpa J.V. Lamour. (Bryopsidales - Chlorophyta) no Estado de Alagoas, Nordeste Brasileiro). O gênero Caulerpa constitui um importante componente da flora ficológica no litoral do Nordeste brasileiro. A presente pesquisa teve como objetivo identificar, descrever e fornecer informações acerca da distribuição e ecologia das espécies do gênero Caulerpa no litoral do Estado de Alagoas, contribuindo para o conhecimento da flora ficológica brasileira, nesse trecho do litoral do Nordeste ainda pouco estudado. Os espécimes foram coletados em seis praias ao longo do litoral alagoano. Foram analisadas também exsicatas de Caulerpa depositadas no Herbário MAC, do Instituto do Meio Ambiente de Alagoas (IMA). Foram identificados quatorze táxons infragenéricos, distribuídos em doze espécies e três variedades, coletados em substratos rochosos e arenosos. Neste trabalho são reportadas pela primeira vez a ocorrência de C. cupressoides var. flabellata, C. kempfii, C. mexicana, C. microphysa, C. verticillata e Caulerpa sp. para o litoral de do Estado de Alagoas.

Palavras-chave: alga verde, Caulerpa, macroalgas, Nordeste do Brasil, taxonomia

\section{Introdução}

Caulerpa é um gênero macroscópico de algas verdes (Bryopsidales - Chlorophyta) que se caracterizam por apresentar talos que se fixam ao substrato por uma massa rizoidal que surgem dos ramos estoloníferos e destes, na posição vertical, surgem os ramos assimiladores eretos de formas variadas (Barata 2008). É um gênero exclusivamente marinho e apresenta ampla distribuição nos mares tropicais e subtropicais, podendo ocorrer também em ambientes de águas frias (Taylor 1960, Silva 2003, Yeh \& Chen 2004, Zaleski \& Murray 2006, Brayner et al. 2008).

1. Universidade Federal de Alagoas, Instituto de Ciências Biológicas e da Saúde, Av. Lourival Melo Mota, s/n., Tabuleiro do Martins, 57072-900 Maceió, AL, Brasil

2. Universidade Federal de Pernambuco, Centro Acadêmico de Vitória, Rua Alto do Reservatório, s/n, Bela Vista, 55608-680 Vitória de Santo Antão, PE, Brasil

3. Autor para correspondência: victorandreirc91@gmail.com 
Assim como as demais espécies da ordem Bryopsidales, os representantes de Caulerpa se destacam na composição florística em termos de diversidade de espécies e se constituem em importantes componentes nas comunidades bênticas de vários ambientes marinhos tropicais e subtropicais (Barata 2008, Bulleri et al. 2010, Guiry \& Guiry 2019). Nestes ambientes, são frequentemente encontrados em substratos móveis (fundos arenosos), podendo também formar densas populações sobre substratos consolidados (recifes de arenito), ocorrendo desde a franja do mesolitoral até regiões mais profundas, até 50 metros de profundidade (Guiry \& Guiry 2019).

Algumas espécies de Caulerpa têm despertado muita atenção e preocupação de diversos pesquisadores e órgãos governamentais por estarem envolvidas em eventos de bioinvasão. Fato este verificado no mar Mediterrâneo desde a década de 70, que vêm sofrendo os efeitos ambientais desastrosos envolvendo pelo menos, duas espécies, C. racemosa e C. taxifolia (Jousson et al. 1998, Meinesz et al. 2001, Velarque et al. 2003, Bulleri 2010, Car et al. 2019). Evidenciam-se também interesses farmacológicos acerca deste gênero, por ser fonte de vitaminas e sais minerais, bem como por possuir princípios bioativos (Trono Jr. 1999). Dentre suas propriedades naturais, cita-se a caulerpina, um alcalóide que possui um grande potencial biológico em diversas atividades antitumorais, antivirais, antioxidantes e antibacterianas (Souza 2011, Padilha 2014).

Atualmente, o gênero engloba 97 táxons infragenéricos taxonomicamente aceitos (Guiry \& Guiry 2019), dos quais, 22 espécies e 16 variedades ocorrem no litoral do Brasil (Moura 2015). A maior diversidade encontra-se registrada no litoral do Nordeste brasileiro com 20 espécies e 13 variedades (Barata 2008, Brayner et al. 2008, Moura 2015).

Ao longo dos anos, as informações taxonômicas e distribuição geográfica sobre as espécies de Caulerpa vêm sendo fornecidas, por meio de diversos estudos florísticos ocorridos ao longo da costa do Nordeste (Ferreira \& Pinheiro 1966, Pereira 1974, Joly \& Pereira 1975, Kanagawa 1984, Oliveira-Carvalho et al. 2003, Brayner et al. 2008). Brayner et al. (2008) registraram 19 táxons infragenéricos de Caulerpa para o litoral do Estado de Pernambuco e Arquipélago de Fernando de Noronha. Neste estudo, algumas espécies apresentaram distribuição restrita na costa de Pernambuco como C. kempfii Joly \& Pereira, C. lanuginosa J. Agardh e C. serrulata (Forssk.) J. Agardh.
A maior contribuição sobre esse grupo foi dada por Barata (2008), que realizou um estudo acurado sobre morfologia e filogenia dos representantes de Caulerpa ocorrentes na costa do Brasil. Através dos dados morfológicos a autora reconheceu 25 táxons infraespecíficos. Alguns táxons como Caulerpa cupressoides var. serrata (Kütz.) Weber Bosse, $C$. cupressoides var. turnerii Weber Bosse, e C. floridana W.R. Taylor não tiveram sua ocorrência confirmada no Brasil. As análises moleculares baseadas nos marcadores tufA do cloroplasto e do ITS rDNA nuclear confirmaram a identificação das espécies feitas através da análise dos caracteres morfológicos de $C$. lanuginosa J. Agardh, C. mexicana (Sond. ex Kütz., C. microphysa (Weber Bosse) Feldmann, C. fastigiata Mont., C. sertularioides (S.G. Gmel.) M. Howe, C. prolifera (Forssk.) J.V. Lamour. e C. webbiana Mont. Ainda neste estudo, alguns táxons se revelaram polifiléticos como C. cupressoides, C. racemosa, C. scalpelliformis e $C$. serrulata), enquanto que, $C$. kempfi e $C$. verticillata, se revelaram parafiléticas.

Apesar de vários estudos listarem e/ou descreverem a expressiva ocorrência do gênero Caulerpa na costa nordestina (Pereira 1974, Brayner et al.2008, Moura 2015, Barata 2008), algumas regiões ainda carecem de informações sobre as espécies de Caulerpa, como por exemplo, o litoral do Estado de Alagoas. Neste trecho do litoral, o conhecimento sobre as macroalgas marinhas bentônicas se deve aos trabalhos de Muniz (1993) e Lemos et al. (2017). Muniz (1993) publicou um checklist onde foram identificados 123 táxons infragenéricos, dos quais 6 espécies e 4 variedades pertencem ao gênero Caulerpa (C. cupressoides, $C$. fastigiata, C. prolifera, $C$. pusilla var. mucronata, $C$. racemosa var. racemosa, $C$. racemosa var. laetevirens e C. scalpelliformis var. denticulata). Posteriormente, Lemos et al. (2017) com base no material depositado no Herbário MAC, do Instituto do Meio Ambiente de Alagoas, listaram 77 táxons infragenéricos de macroalgas, incluindo 5 espécies e 1 variedade de Caulerpa (C. cupressoides, C. cupressoides var. lycopodium, C. fastigiata, C. racemosa, C. scalpelliformis e C. sertularioides) pertencentes ao gênero Caulerpa.

Com o intuito de contribuir para o conhecimento dos representantes de Caulerpa no litoral do Nordeste brasileiro, o presente trabalho teve como objetivo reunir informações taxonômicas, ecológicas e distribuição geográfica das espécies que ocorrem na região entremarés ao longo do litoral do Estado de Alagoas. 


\section{Material e métodos}

Área de Estudo - O litoral do Estado de Alagoas ( $8^{\circ} 54^{\prime} 50^{\prime \prime} \mathrm{S}-35^{\circ} 9^{\prime} 33^{\prime \prime} \mathrm{O}$ e $\left.10^{\circ} 30^{\prime} 24^{\prime \prime} \mathrm{S}-36^{\circ} 23^{\prime} 42^{\prime \prime O}\right)$ está localizado na região ficogeográfica tropical (Horta et al. 2001). Possui cerca de $230 \mathrm{~km}$ de extensão, tendo como limite norte a praia de São José da Coroa Grande, no Estado de Pernambuco e ao sul a praia de Brejo Grande, no Estado do Sergipe (figura 1). O clima da região é tropical do tipo AS', segundo a classificação de Köppen. A temperatura média anual varia de $12{ }^{\circ} \mathrm{C}$ a $31{ }^{\circ} \mathrm{C}$, com pluviometria regular anual de 1478,6 $\mathrm{mm}$ por ano. A região apresenta duas estações anuais bem definidas: seca (setembro a fevereiro) e chuvosa (março a agosto) (Santos 2004).

O litoral do Estado de Alagoas está subdividido em três regiões: litoral norte, central e sul. O litoral norte situa-se entre a foz do Rio Persinunga, fronteira com o Estado de Pernambuco, até o Município de Paripueira, abrangendo dez municípios. Nessa região, existem inúmeros recifes de arenito que ficam expostos durante as baixa-mares. Há também áreas recifais constituídas por recifes de arenito tipo "franja", que ficam totalmente submersos durante as baixa-mares, formando manchas irregulares. Dessa forma, sua geomorfologia minimiza o hidrodinamismo intenso do mar, tornando o ambiente recifal propício para o desenvolvimento da vida marinha (Correia \& Sovierzoski 2005). Essa região está situada dentro da APA Costa dos Corais, que abrange parte do litoral sul do Estado de Pernambuco (a partir do Município de Tamandaré) até o litoral norte do Estado de Alagoas (Município de Paripueira), correspondendo uma área total de 413 mil hectares.

O litoral Central é constituído por 11 municípios, incluindo a capital Maceió. Ao longo desse trecho, ocorrem inúmeras praias e recifes de arenito, tornando-se a parte mais extensa do litoral de Alagoas. As formações recifais ficam localizadas junto à linha de costa, incluindo os recifes de arenito do tipo "barreira" que são lineares e paralelos. Há também ocorrência de recifes de coral, formando grandes manchas irregulares. Além disso, ocorrem áreas bastante significativas de manguezais principalmente ao longo dos canais (Correia \& Sovierzoski 2005).

O litoral sul engloba três municípios (Feliz Deserto, Coruripe e Piaçabuçu). Nessa região, a grande maioria dos recifes é constituída por cordões de arenito, com várias formações submersas, paralelos à linha da costa, formando grandes barreiras. Os manguezais são menores, pois os rios que deságuam neste litoral apresentam menor volume de águas e conseqüentemente também menores áreas estuarinas (Correia \& Sovierzoski 2005).

Em geral, ao longo do litoral, as formações recifais são constituídas em grande parte de recifes de arenito, com frequente ocorrência de corais e rodólitos associados, geralmente submersos durante as marés baixas. As referidas formações apresentam padrões geomorfológicos muito distintos, podendo variar entre franja e barreira. Tais formações são descontínuas, pouco elevadas, frequentemente alongadas e usualmente próximos e paralelos à linha da costa. São responsáveis por minimizar a erosão marinha, tornando o ambiente recifal propício para a vida marinha (Correia \& Sovierszoski 2005). A maioria dos organismos bentônicos é encontrada fixa em substratos consolidados (rochas de arenito, rodólitos ou exoesqueletos de cnidários mortos). $\mathrm{Na}$ área estudada, ocorrem também substratos não consolidados, formados por sedimentos finos ou por fragmentos de Halimeda opuntia (L.) J.V. Lamour., que margeiam os recifes, onde é comum encontrar sedimentos recobrindo os recifes, especialmente em épocas de maior pluviosidade.

$\mathrm{Na}$ área estudada, foi possível identificar diversos microambientes recifais conforme a metodologia aplicada por Nunes \& Paula (2002). Nos municípios de Maragogi, Paripueira, Sonho Verde, Riacho Doce e Pajuçara os recifes são do tipo franja, pouco elevados e irregulares. Nessas áreas recifais foram determinados quatro compartimentos: região frontal do recife (RFR), região protegida do recife (RPR), topo recifal (TR) e

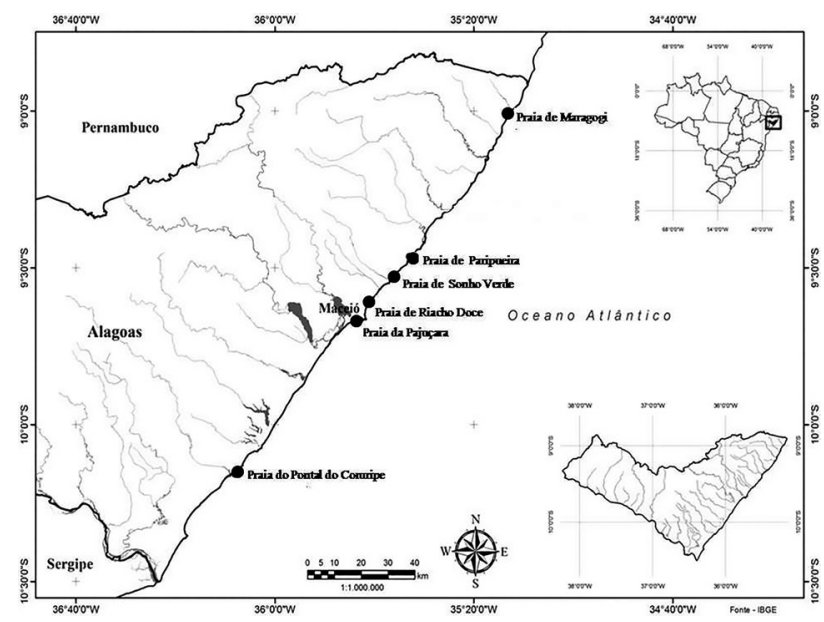

Figura 1. Mapa do litoral do Estado de Alagoas com as respectivas praias coletadas.

Figure 1. Map of Alagoas State coast with respective collecting sites. 
poças de maré (Pçs). No entanto, os recifes do Pontal do Coruripe são representados por recife do tipo barreira, elevado, lineares e estreitos, onde foram determinados quatro compartimentos recifais: região frontal do recife (RFR), platô recifal (PR), região protegida do recife (RPR) e laguna recifal (LR).

Coleta e análise de dados - Em função da diversidade algal e de microambientes recifais, foram escolhidas seis praias ao longo do litoral do Estado de Alagoas: três localizadas no litoral norte: Maragogi $\left(35^{\circ} 13^{\prime} 4^{\prime \prime} \mathrm{O}-\right.$ $\left.9^{\circ} 0^{\prime} 49^{\prime \prime} \mathrm{S}\right)$, Paripueira (3532'37"O-9²8'26"S) e Sonho

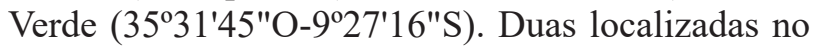
litoral Central: Riacho Doce ( $\left.9^{\circ} 34^{\prime} 26,8^{\prime \prime S}-35^{\circ} 39^{\prime} 17^{\prime \prime} \mathrm{O}\right)$ e Pajuçara $\left(9^{\circ} 39^{\prime} 53^{\prime \prime S}-35^{\circ} 41^{\prime} 43^{\prime \prime} \mathrm{O}\right)$. Uma no litoral Sul: Pontal do Coruripe $\left(10^{\circ} 09^{\prime} 38^{\prime \prime S}-36^{\circ} 08^{\prime} 04^{\prime \prime O}\right)$. As coletas foram realizadas durante o período seco (fevereiro; setembro e dezembro/2015; fevereiro/2016 e março/2018) e no período chuvoso (maio, junho e julho/2015 e agosto/2016).

Os espécimes de Caulerpa foram coletados na região entremarés com auxílio de espátulas e nas poças recifais através de mergulhos livres. Os exemplares foram acondicionados em sacos plásticos devidamente etiquetados. No Laboratório da Universidade Federal de Alagoas, procedeu-se a triagem, fixação e conservação em formol (4\%). Como material adicional, foram analisadas 30 exsicatas de Caulerpa pertencentes ao Herbário MAC do Instituto do Meio Ambiente do Estado de Alagoas (IMA-AL).
A identificação foi baseada em caracteres morfológicos diagnósticos do gênero Caulerpa (forma, dimensões e disposição dos râmulos nos ramos assimiladores), por meio de bibliografias pertinentes (Coppejans \& Beeckman 1990, Ertan et al. 1998, Famà et al. 2002, Barata 2008, Brayner et al. 2008, Belton et al. 2014, Draisma et al. 2014). As estruturas analisadas foram mensuradas com auxílio de régua milimetrada e as médias fornecidas nas descrições foram baseadas em 10 medidas por estrutura analisada. As fotografias foram obtidas com Câmera Digital NX2000, acoplada ao estereomicroscópio ou microscópio óptico binocular. A ordenação taxonômica e a sinopse dos táxons foram feitas de acordo com Wynne (2017) e o refinamento de nomes científicos das espécies foi confirmado através do banco de dados AlgaeBase (Guiry \&Guiry 2019). O material coletado na presente pesquisa foi herborizado seguindo as técnicas usuais de Fidalgo \& Bononi (1984) e as exsicatas incorporadas ao acervo do Herbário MAC.

\section{Resultados e Discussão}

Para o litoral do Estado de Alagoas foram identificados 14 táxons infragenéricos, distribuídos em 12 espécies e três variedades (tabela 1), as quais podem ser identificadas pela chave apresentada.

\section{Chave identificação de Caulerpa para o litoral do Estado de Alagoas}

1. Talo completamente filamentoso; porção prostrada e ramos assimiladores morfologicamente semelhantes C. fastigiata

1.Talo com estolão cilíndrico; porção prostrada e ramos assimiladores morfologicamente distintos

2. Ramos assimiladores achatados ou em forma de fita

3. Ramos assimiladores em forma de fita, com margem lisa; râmulos ausentes C. prolifera

3. Ramos assimiladores achatados, râmulos presentes

4. Râmulos sem constrição na base, com margem frequentemente denteada C. denticulata

4. Râmulos com constrição na base; margem lisa

5. Râmulos falciformes sobrepostos C. mexicana

5. Râmulos ovalados não sobrepostos Caulerpa sp.

2. Ramos assimiladores cilíndricos ou filamentosos

6. Ramos assimiladores portando verticilos sobrepostos, ramificados dicotomicamente

7. Estolão recoberto por minúsculos pelos lanuginosos; verticilos inconspícuos; râmulos com marcada constrição na base das ramificações C. kempfii

7. Estolão glabro; verticilos conspícuos em números de 2-5 por ramo assimilador; constrição na base das ramificações ausentes C. verticillata

6. Ramos assimiladores portando râmulos globosos, peltados, clavados, maniliformes ou cilíndricos

8. Râmulos mamiliformes ou espinescentes recobrindo totalmente o ramo assimilador, dispostos radialmente, podendo ser também de forma dística ou trística C. cupressoides

8. Râmulos de formas diversas 
9. Ramos assimiladores com râmulos cilíndricos distribuídos disticamente no eixo central, dando com aspecto penado

C. sertularioides

9. Râmulos esféricos ou globosos

10. Estolão densamente intricado; Râmulos esféricos em números de 1-8 por ramo assimilador ....... C. microphysa

10. Estolão pouco intricado; Râmulos com ápice globoso ou peltado com quantidade variável por ramo assimilador

11. Râmulos apresentando ápices arredondados

C. racemosa

11. Râmulos apresentando ápices peltados

C. chemnitzia

Tabela 1. Relação dos táxons infragenéricos de Caulerpa ocorrentes no litoral do Estado de Alagoas.

Table 1. Caulerpa infrageneric taxa found on the Alagoas State coast.

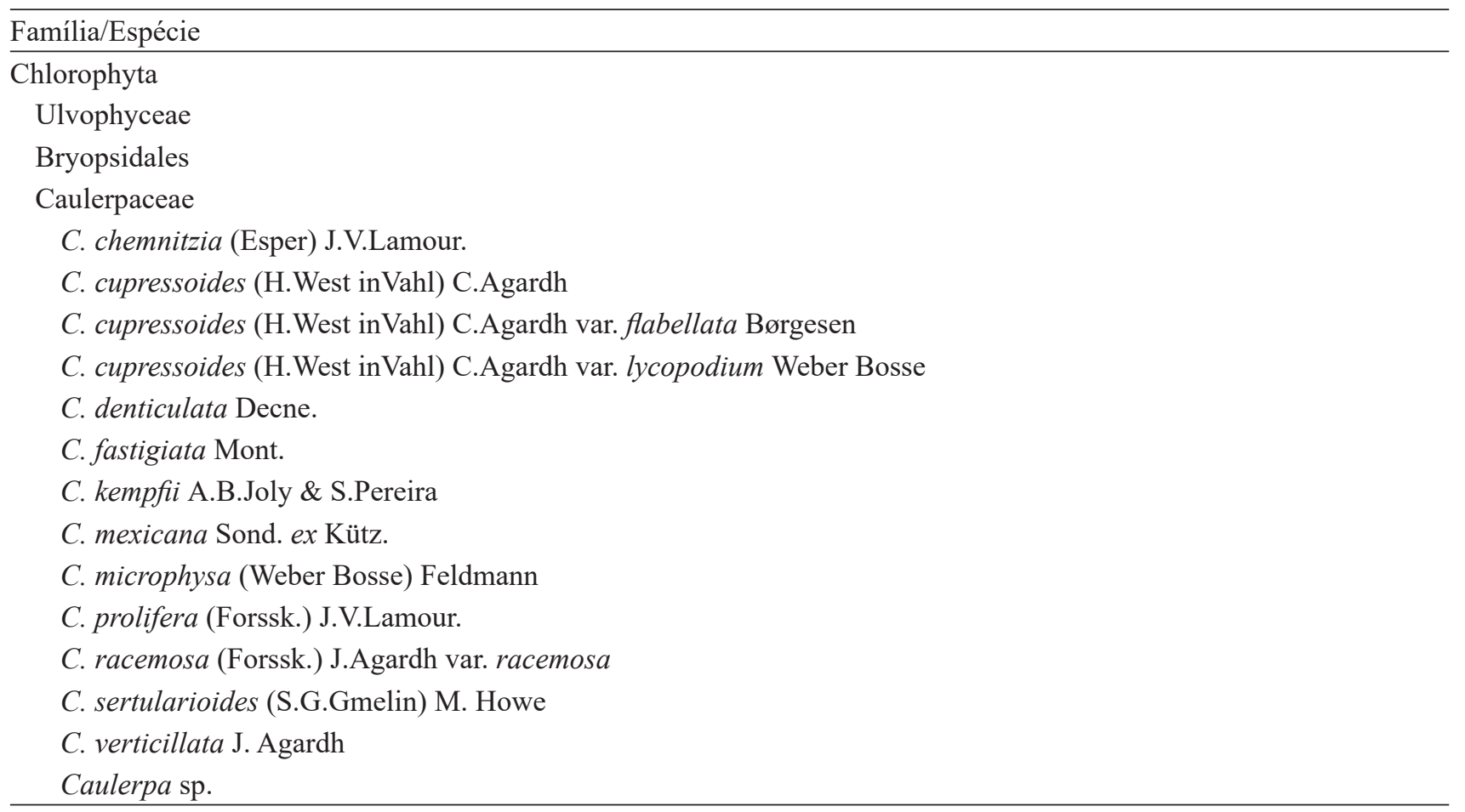

\section{Descrição das espécies analisadas}

Caulerpa chemnitzia (Esper) J.V.Lamour. Lamouroux, J.V.F. (1809). Nouveau Bulletin des Sciences, par la Société Philomathique de Paris 1: 330-333, fig. 2, pl. 6. Localidade tipo: Costa de Malabar, Índia.

Basionimo: Fucus chemnitzia Esper.

Figura 2 a, b, c, d

Talo de consistência carnosa, verde-claro, com até $13,3 \mathrm{~cm}$ de altura, fixo ao substrato por ramos rizoidais filamentosos, ramificados. Estolão glabro, cilíndrico e ramificado, com 0,5-3,3 mm de diâmetro. Ramos assimiladores cilíndricos, com 0,5-13,1 cm de altura e 1,3-7,2 mm de largura. Râmulos raramente sésseis ou sustentados por longos pedúnculos, ápice globóide a peltado, revestindo densamente ou de maneira esparsa o eixo do ramo assimilador, com 0,9-5,2 mm de comprimento e 0,67-5,5 mm de diâmetro.

Material examinado: Brasil. AlagoAs: Maceió, Praia da Ponta Verde, 23-I-1984, M.J.B.Mendes 147 \& I.S.Moreira (MAC3339); Praia da Jatiúca, 23-I-1984, M.J.B.Mendes 104 \& I.S.Moreira (MAC3340); Praia de Ipioca, 25-IV-1986, M.J.B.Mendes 132, I.S. Moreira, A.I.Pinheiro \& U.Omena (MAC5017); Praia da Garça Torta, 24-IV-1986, M.J.B. Mendes 302, I.S. Moreira \& A.I.L. Pinheiro (MAC5031); Praia da Garça Torta, 24-IV-1986, M.J.B. Mendes 300, I.S. Moreira, A.I. Pinheiro \& U. Omena (MAC5034); Praia do Sobral, 27-II-1986, M.J.B. Mendes 310, I.S. Moreira \& A.I. Pinheiro (MAC5036); Praia da Pajuçara, 27-II-1986, M.J.B. Mendes 314, I.S. Moreira 

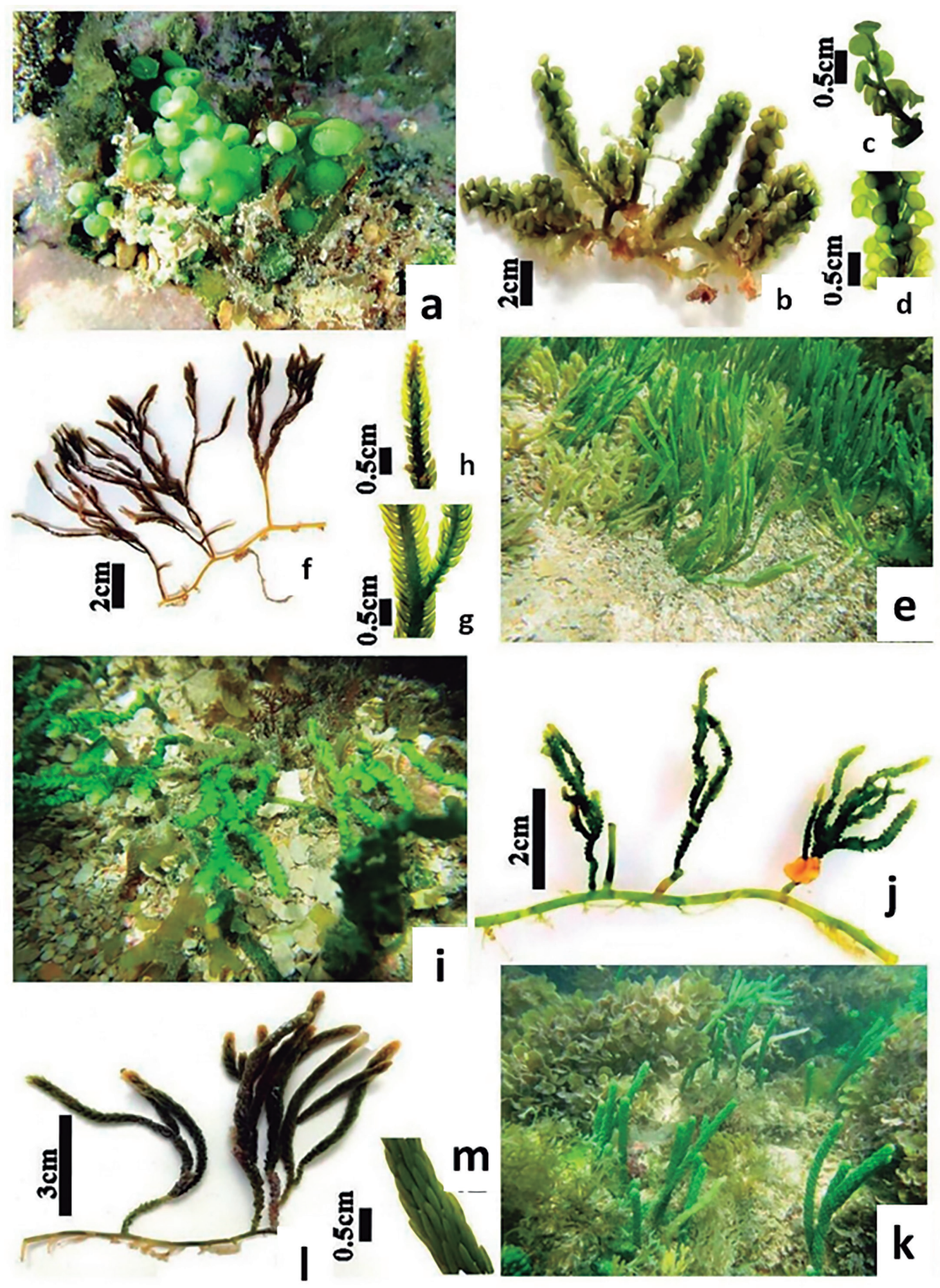

Figura 2. Caulerpa chemnitzia. a. Hábito do talo em ambiente natural. b. Hábito geral do talo. c, d. Detalhe de parte de um ramo assimilador com râmulos peltados. Caulerpa cupressoides. e. Hábito do talo em ambiente natural. f. Hábito geral do talo. g. Parte de um ramo assimilador com pínulas dísticas. h. Detalhe do ápice do ramo assimilador com pínulas trísticas. Caulerpa cupressoides var. flabellata. i. Hábito do talo em ambiente natural. j. Hábito geral do talo. Caulerpa cupressoides var. lycopodium. k. Hábito do talo em ambiente natural. 1. Aspecto geral do talo. $\mathrm{m}$. Detalhe de parte do ramo assimilador recoberto por numerosos râmulos mamiliformes.

Figure 2. Caulerpa chemnitzia. a. Habit in natural environment. b. Habit of the thallus. c, d. Detail of assimilator branch with peltate branchlets. Caulerpa cupressoides. e. Habit in natural environment. $\mathrm{f}$. Habit of the thallus. g. Detail of assimilator branch with pinnae arranged in two rows. h. Detail of assimilator branch with pinnae arranged in tree rows. Caulerpa cupressoides var. flabellata. i. Habit in natural environment. j. Habit of the thallus. Caulerpa cupressoides var. lycopodium. k. Habit in natural environment. 1. Habit of the thallus. m. Detail of assimilator branch covered by numerous branchlets. 
\& A.I. Pinheiro (MAC5037); Praia de Guaxuma, 28-II-1986, M.J.B. Mendes 341, I.S. Moreira \& A.I. Pinheiro (MAC5069); Praia de Ipioca, 19-VIII-1986, M.J.B. Mendes 46, J.E. Nascimento \& U. Omena (MAC5167); Praia de Riacho Doce, 19-09-2009, E.A.C.Guedes, E.S.M. Rêgo, \& L.D. Barros, s/n (MAC51229); Paripueira, Praia de Paripueira, 18-V-2014, V.A.R. Carneiro 62 \& S. Rodrigues (MAC59052); São Miguel dos Milagres, Praia de São Miguel dos Milagres, 4-VII-2007, M.J.F. Silva, E.A.C. Guedes \& L.L.M.V. Nova s/n (MAC59122); Piaçabuçu, Praia do Pontal do Peba, 4-VII-2007, M.J.F. Silva, E.A.C. Guedes \& L.L.M.V. Nova $s / n$ (MAC59123).

C. chemnitzia foi encontrada em todas as estações de coleta. Os espécimes foram coletados predominantemente sobre substratos rochosos em áreas recifais expostas durante a maré baixa no mediolitoral, formando bancos bem desenvolvidos. Foi possível verificar que os espécimes apresentaram notável plasticidade fenotípica, principalmente na morfologia dos ramos assimiladores e râmulos. Os exemplares coletados em áreas expostas a insolação no topo recifal, na região protegida do recife e na região frontal do recife possuíam râmulos clavados densamente arranjados em torno dos ramos assimiladores, bem como talos mais desenvolvidos, características típicas da antiga $C$. racemosa var. occidentalis. Por outro lado, os exemplares correspondentes à antiga variedade peltata, apresentaram talos menores e râmulos peltados pouco numerosos foram coletados unicamente em áreas sombreadas da região protegida do recife ou em poças, em meio a fendas ou depressões do recife, do médio ao infralitoral. Foram encontrados exemplares crescendo associados à Amphiroa anastomosans Weber Bosse, Gelidiella acerosa (Forssk.) Feldmann \& G. Hamel., Gelidium crinale (Hare ex Turner) Gaillon, Halimeda opuntia (L.) J.V. Lamour., Hypnea spinella (C.Agardh) Kütz., Palisada perforata (Bory) K.W. Nam e Valonia aegagropila C. Agardh. Alguns indivíduos abrigavam como epífitas Dictyopteris delicatula J.V. Lamour. e Hypnea pseudomusciformis Nauer, Cassano e M.C. Oliveira.

Caulerpa cupressoides (Vahl) C.Agardh. Agardh, C.A. (1817). Synopsis algarum Scandinaviae, adjecta dispositione universali algarum.pp. [i]-xl,[1]135. Lundae [Lund]: ex officina Berlingiana. Localidade-tipo: St Croix, Ilhas Virgens (Caribe). Basiônimo: Fucus cupressoides Vahl

Figura $2 \mathrm{e}, \mathrm{f}, \mathrm{g}, \mathrm{h}$
Talo de coloração verde-escura, textura rígida, com até $16,5 \mathrm{~cm}$ de altura. Fixo ao substrato por ramos rizoidais, filamentosos, ramificados, com coloração variando de amarela a translúcida, com 0,25-9,2 cm de comprimento. Estolão glabro, cilíndrico, ramificado, com 1,2-2,0 mm de diâmetro. Ramos assimiladores simples, podendo ser ramificados, cilíndricos, eretos a levemente retorcidos, desnudos na porção basal e acima deste, recoberto por râmulos cônicos e espinescentes, sésseis ou com ligeira constrição na base. Râmulos distribuídos ao longo do eixo central de forma radial, distribuídos predominantemente de forma dística, podendo também ser de forma trística, ápice mucronado com 0,2-1,7 $\mathrm{mm}$ de comprimento e $1 \mathrm{~mm}$ de diâmetro.

Material examinado: Brasil. AlagoAs: Maceió, Praia da Jatiúca, 4-V-1982, M.J.B. Mendes 148 (MAC2900); Praia da Ponta Verde, 4-V-1982, M.J.B. Mendes 149 (MAC2901); Praia da Garça Torta, 25-III-1986, M.J.B.Mendes 350, A.I.L. Pinheiro, I.S. Moreira \& U. Omena (MAC5070); Praia da Garça Torta, 29-X-1986, M.J.B. Mendes 359, A.I.L. Pinheiro, I.S. Moreira \& U. Omena (MAC5114); Praia da Garça Torta, 26-VI-1986, M.J.B.Mendes 22, A.I.L. Pinheiro, I.S. Moreira \& U. Omena (MAC5147); Praia da Pajuçara, 12-VII-2014, V.A.R. Carneiro 100 \& S. Rodrigues (MAC58959); Praia da Pajuçara, 17-V-2014, V.A.R. Carneiro 95 (MAC58969); Paripueira, Praia de Paripueira 17-VI-2014, V.A.R. Carneiro 64 \& S. Rodrigues (MAC59054).

Caulerpa cupressoides ocorreu apenas em três praias (Riacho Doce, Sonho Verde e Pajuçara). Os exemplares foram coletados tanto em substrato rochoso como arenoso. A espécie ocorreu em poças rasas e extensas, em topos recifais não elevados e em lagunas recifais do médio ao infralitoral. Foram observados que alguns exemplares cresciam associados à Halimeda opuntia, Hypnea spinella e Palisada perforata. Alguns exemplares abrigavam como epífitas Canistrocarpus cervicornis (Kütz.) De Paula \& De Clerck, Dictyopteris delicatula, Jania capillacea Harv. e coralináceas não geniculadas.

Barata (2008) observou a recorrente ocorrência de ecades (formas intermediárias) nas variedades e formas correspondentes ao material brasileiro, tendo em vista que os dados moleculares gerados pela autora não deram suporte para separação de categorias infraespecíficas para os espécimes de râmulos curtos dispostos de forma dística a trística. Devido à frequente presença de ecades no material alagoano, 
bem como na dificuldade de encontrar caracteres diagnósticos mais estáveis, preferiu-se identificar todos os exemplares com râmulos curto dispostos de forma dística a trística apenas em nível de espécie, $C$. cupressoides.

Entretanto, Barata (2008) ao analisar o material brasileiro de Caulerpa disttinto dos padrões citados acima, reconheceu dentro do "Complexo C. cupressoides", três variedades, a saber, $C$. cupressoides var. flabellata, C. cupressoides var. mamillosa e C. cupressoides var. lycopodium. Dentre estas, duas foram registradas na presente pesquisa e podem ser identificadas pela chave dicotômica abaixo:

1. Eixo central dos ramos assimiladores densamente recobertos por râmulos mamiliformes .... C. cupressoides var. lycopodium

1. Eixo central dos ramos assimiladores evidente, portando râmulos espinescentes dispostos disticamente ... C. cupressoides var.flabellata

Caulerpa cupressoides (Vahl) C.Agardh var. flabellata Børgesen Kongelige Danske Vidensk abernes Selskabs Skrifter, 7. Raekke, Naturvidens kabelig og Mathematiskafdeling 4: 337-392, 31 figs. Localidadetipo: St. Jan (St. John) e St. Thomas, Ilhas Virgens, Caribe.

Figura $2 \mathrm{i}, \mathrm{j}$

Talo de textura rígida, verde-claro a verdeescuro com até $4,8 \mathrm{~cm}$ de altura. Fixo ao substrato por ramos rizoidais filamentosos, variando de amarelada a esbranquiçada, com $0,5-0,8 \mathrm{~cm}$ de comprimento. Estolão glabro, cilíndrico e amarelado com 1,0-2,3 mm de diâmetro. Ramos assimiladores verdes-escuros, achatados, podendo ser simples ou ramificados, frequentemente retorcidos, com 1,8-4,6 de altura e 2-2,5 $\mathrm{mm}$ de largura, fixados por um curto pedúnculo de 0,2-0,4 cm de comprimento. Râmulos curtos, espinescentes, quase sésseis, dispostos de forma dística, raramente trística no eixo do ramo assimilador, com ápices mucronados.

Material examinado: Brasil. Alagons: Maceió, Praia de Riacho Doce, 16-XI-2016, V.A.R. Carneiro 177, J.O.F. Brito, M. Fireman \& E.A.C. Guedes (MAC59237); Praia da Pajuçara, Piscina do Amor, 18-IX-2015, V.A.R. Carneiro \& F.E.G.Q. Lima (MAC58730).Praia da Garça Torta, 28-II-1986, M.J.B. Mendes 277, A.I.L. Pinheiro \& I.S. Moreira (MAC59395).

C. cupressoides var. flabellata foi encontrada ocorrendo apenas no litoral central de Alagoas, nas praias da Pajuçara e Riacho Doce. Na praia da Pajuçara, foram coletados em poças recifais do infralitoral sobre substrato rochoso, em locais poucos iluminados. $\mathrm{Na}$ praia de Riacho Doce, foram encontrados em substrato arenoso nas poças recifais rasas. Alguns exemplares cresciam associados à Chondracanthus acicularis (Roth) Fredericq., Halimeda opuntia, Gelidiella acerosa e abrigavam como epífitas Hypnea pseudomusciformis e coralináceas incrustantes.

Caulerpa cupressoides (Vahl) C. Agardh var. lycopodium Weber Bosse. Annales du Jardin Botanique de Buitenzorg 15:335, 1898. Caulerpa lycopodium J.Agardh, ÖfversigtafKongl. [Svenska] Vetenskaps-Akademies Förhandlingar 4: 6. 1847. nom. illeg. Localidade tipo: "mari Brasiliae et Indiae Occidentalis". Basiônimo: Fucus cupressoides Vahl. Skrift. Naturh.-Selsk. p. 29, 1802

Figura $2 \mathrm{k}, 1, \mathrm{~m}$

Talo de coloração verde-clara a verde-escura, textura rígida com até $14,8 \mathrm{~cm}$ de altura. Fixo ao substrato por meio de ramos rizoidais filamentosos, hialinos com 0,25-10,2 cm de comprimento. Estolão glabro, cilíndrico, ramificado, com 1,2-2,4 mm de diâmetro. Ramos assimiladores cilíndricos, podendo ser simples ou ramificados, desnudos na porção basal e acima deste, revestidos por inúmeros râmulos densamente compactados, com 2,4-14,6 cm de altura. Râmulos mamiliformes, sésseis ou pedunculados, apresentando ápice mucronado.

Material examinado: Brasil. AlagoAs: São Miguel dos Milagres, Praia de São Miguel dos Milagres, 4-VII-2007, M.J.F. Silva, E.A.C. Guedes \& L.L.M.V. Nova $s / n$ (MAC59120); Paripueira, Praia de Paripueira, 18-V-2014, V.A.R. Carneiro 63 \& S. Rodrigues (MAC59051). Maceió, Praia da Garça Torta, 24-IV-1986, M.J.B. Mendes, A.I.L. Pinheiro, I.S. Moreira \& U. Omena s/n (MAC5043); Praia da Garça Torta, 25-III-1986, M.J.B. Mendes 146, A.I.L. Pinheiro \& I.S. Moreira (MAC5007); Praia da Pajuçara, 26-III-1986, M.J.B. Mendes 118, A.I.L. Pinheiro \& I.S. Moreira (MAC5021); Praia da Ponta Verde, 2-XII-1986, M.J.B. Mendes 191 (MAC5113); Praia de Ipioca, 23-VIII-1986, M.J.B. Mendes, J.E. Nascimento \& U. Omena (MAC5164).

C. cupressoides var. lycopodium foi encontrada crescendo sobre substrato arenoso em poças recifais e topos recifais pouco elevados, sempre em áreas expostas à insolação. Também foram encontrados, com menos frequência, em substratos rochosos de 

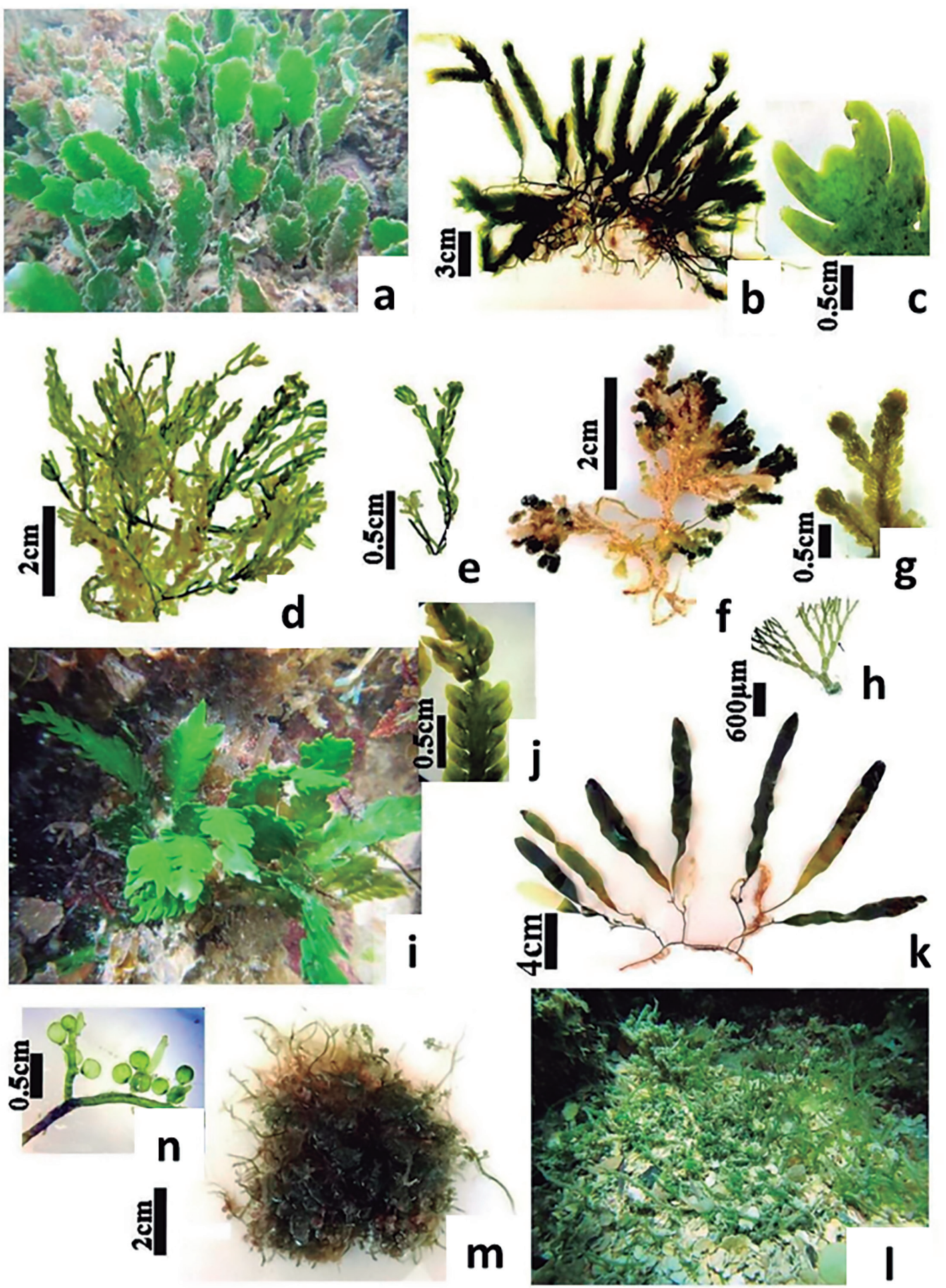

Figura 3. Caulerpa denticulata. a. Hábito do talo em ambiente natural. b. Hábito geral do talo. c. Detalhe de parte do ramo. Caulerpa fastigiata. d. Hábito geral do talo. e. Detalhe de parte do ramo. Caulerpa kempfii. f. Hábito geral do talo. g. Detalhe do ramo densamente coberto por verticilos filamentosos. h. Detalhe de parte do verticilo com râmulos ramificados dicotomicamente. Caulerpa mexicana. i. Hábito do talo em ambiente natural. j. Detalhe de parte de um ramo portando pínulas falciformes. Caulerpa prolifera. k. Hábito geral do talo. Caulerpa microphysa. 1. Hábito do talo em ambiente natural. m. Hábito geral do talo. n. Detalhe de parte de um ramo portando râmulos globóides.

Figure 3. Caulerpa denticulata. a. Habit in natural environment. b. Habit of the thallus. c. Detail of assimilator branch. Caulerpa fastigiata . d. Habit of the thallus. e. Detail of assimilator branch. Caulerpa kempfii. f. Habit of the thallus. g. Detail of assimilator branch densely covered by filamentous whorls. h. Detail of whorl with dichotomous branchlets. Caulerpa mexicana. i. Habit in natural environment. j. Detail of assimilator branch with falciform pinnae. Caulerpa prolifera. k. Habit of the thallus. Caulerpa microphysa. 1 Habit in natural environment. m. Habit of the thallus. $n$. Detail of assimilator branch with spherical branchlets. 
reentrâncias da região protegida do recife, do médio ao infralitoral.

Caulerpa denticulata Decne.1841: 120-121, pl. VI.B. Localidade-tipo: Mar Vermelho

Figura $3 \mathrm{a}, \mathrm{b}, \mathrm{c}$

Talo de coloração verde-clara a verde-escuro, podendo ser amarelada, consistência firme com até $25,2 \mathrm{~cm}$ de altura. Fixo ao substrato por ramos rizoidais, filamentosos, com 0,5-1,5 cm de comprimento. Estolão glabro, cilíndrico, ramificado com até 1-3 mm de diâmetro. Ramos assimiladores, achatados, eretos, com 6,1-25 cm de altura e 0,5-2,0 $\mathrm{cm}$ de largura, conectados à porção estolonífera por um curto pedúnculo cilíndrico com $0,3-1 \mathrm{~cm}$ de comprimento e 1,2-2 mm de diâmetro. Râmulos simples, achatados, dispostos de maneira dística no ramo assimilador, portando minúsculas projeções espinescentes desde a margem mediana ao ápice, sendo recurvados em direção ao eixo central, com $0,2-0,5 \mathrm{~cm}$ de largura e 0,4-0,8 cm de comprimento.

Material examinado: Brasil. AlagoAs: Coruripe, Praia do Pontal do Coruripe, 21-VI-2016, V.A.R. Carneiro 508, J.O. F.Brito, F.E.G.Q. Lima \& E.A.C. Guedes (MAC59383). Maceió, Praia da Jatiúca, 4-V-1982, M.J.B. Mendes 106 (MAC2902). Praia de Ipioca, 25-IV-1986, M.J.B. Mendes 131, A.I.L. Pinheiro, I.S. Moreira \& U. Omena (MAC5016); Praia da Garça Torta, 24-IV-1986, M.J.B. Mendes 309, A.I.L. Pinheiro \& I.S. Moreira (MAC5050); Praia da Ponta Verde, 29-V-1986, M.J.B. Mendes 321, A.I.L. Pinheiro \& I.S. Moreira (MAC5053). Praia da Pajuçara, 27-II-1986, M.J.B. Mendes 332, A.I.L. Pinheiro \& I.S. Moreira (MAC5075). Praia da Garça Torta, 29-VI-1986, M.J.B. Mendes 12, A.I.L. Pinheiro, I.S. Moreira \& U. Omena (MAC5138); Praia de Ipioca, 25-IV-1986, M.J.B. Mendes, A.I.L. Pinheiro, I.S. Moreira \& U. Omena, $s / n$ (MAC5638).

Espécie bastante frequente no litoral alagoano, tendo sido encontrada em todas as localidades de coleta. Os exemplares coletados foram encontrados em diferentes tipos de substratos, do médio ao infralitoral, tanto em áreas expostas, como protegidas do hidrodinamismo e insolação. Na praia do Pontal do Coruripe, foram observados bancos de $C$. denticulata na laguna recifal, em substrato arenoso-lodoso, crescendo associada a prados de Halodule wrightii Ascherson e outras macroalgas. O mesmo ocorreu na região protegida do recife, em topos recifais e em poças, onde a espécie se encontrava na mesma condição, porém formando bancos extensos sobre o substrato rochoso, crescendo associada a outras macroalgas. Alguns exemplares foram observados crescendo em fendas localizadas no platô recifal. Alguns exemplares cresciam associados à Bryopsis plumosa (Hudson) C.Agardh, Caulerpa microphysa, Caulerpa sertularioides, G. acerosa e Hypnea spinella e abrigavam como epífitas Dictyopteris delicatula e Hypnea pseudomusciformis.

Caulerpa fastigiata Mont. Annales des Sciences Naturalles, Botanique, ser. 2,8: 353-354. 1837. Localidade tipo: Cuba.

Figura 3 d, e

Talo de coloração verde-clara, completamente filamentoso, formando densos tufos de textura macia, com até $2 \mathrm{~cm}$ de altura, fixo ao substrato por filamentos rizoidais ramificados, de tonalidade geralmente amarelada; estolão ramificado, geralmente amarelado, com 0,4-0,5 mm de diâmetro; ramos assimiladores simples ou ramificados, portando séries de 1-7 de pequenos agrupamentos de râmulos claviformes, simples, em números de 3-8 com ramificação oposta, alterna ou irregular, com 1,75-2,5 $\mathrm{mm}$ de comprimento e 0,1-0,2 mm de diâmetro.

Material examinado: Brasil. Alagoas: Paripueira, Praia de Sonho Verde, 29-XI-2015, V.A.R. Carneiro 187, J.O.F. Brito \& E.A.C. Guedes (MAC58823); Coruripe, Praia do Pontal do Coruripe, 21-II-2015, V.A.R. Carneiro 452 (MAC58899). Marechal Deodoro, Praia do Saco de Pedra, 28-X-1987, M.J.B. Mendes 543, A.D.J. Matos \& J.J. Santos (MAC5610); Praia do Francês, 20-XI-1987, M.J.B. Mendes 546, A.D.J. Matos \& J.J. Santos (MAC5613).

Espécie pouco comum na área de estudo, tendo sido encontrada apenas nas Praias de Sonho Verde e Pontal do Coruripe. Na praia de Sonho Verde, densos tufos foram encontrados em pequenas poças próximas à região frontal do recife em área frequentemente sombreada efundo arenoso, totalmente descoberto durante a maré baixa. Na praia do Pontal do Coruripe, os exemplares foram encontrados no mediolitoral em áreas protegidas da região protegida do recife, crescendo em poças recifais ou reentrâncias, sobre substrato rochoso.

Caulerpa kempfii A.B.Joly \& S.Pereira Joly et Pereira, Ciênc. e Cult.p. 417. 1975. Localidade-tipo: Pernambuco, Brasil.

Figura $3 \mathrm{f}, \mathrm{g}, \mathrm{h}$ 
Talo verde-escuro, delicado, com até $2,7 \mathrm{~cm}$ de altura. Fixo ao substrato por ramos rizoidais filamentosos, de coloração geralmente amarelada e por minúsculos pelos lanuginosos, translúcidos, que revestem o estolão e a base dos ramos assimiladores. Estolão cilíndrico, ramificado, com 0,2-0,8 mm de diâmetro. Ramos assimiladores simples ou ramificados com base nua, acima desta, portam verticilos filamentosos que o cobrem completamente, com até $2,5 \mathrm{~cm}$ de altura. Os verticilos apresentam râmulos dicotômicos até $5^{\text {a }}$ ordem, curvados em direção ao ápice, com marcada constrição na base das ramificações. Ápices dos râmulos emarginados, uni ou bimucronados, apresentando múcrons divergentes.

Material examinado: Brasil. Alagoas: Maragogi, Praia de Maragogi, 19-III-2018, F.E.G.Q. Lima 23 (MAC59858).

Um único exemplar foi coletado na praia de Maragogi durante o período seco (março de 2018). A espécie foi encontrada em topos recifais submersos do infralitoral, crescendo sobre substrato rochoso recoberto por sedimentos finos, associada à Caulerpa. verticillata e Halimeda opuntia.

Caulerpa mexicana Sond. ex Kütz. Kützing, F.T. (1849). Species algarum. pp. [i]-vi, [1]-922. Lipsiae [Leipzig]: F.A. Brockhaus. Localidade-tipo: México. Figura $3 \mathrm{i}, \mathrm{j}$

Talo verde-escuro, de consistência firme, com até $7,8 \mathrm{~cm}$ de altura. Fixo ao substrato por diminutos ramos rizoidais, filamentosos, de tonalidade amarelada, com 0,3-1,2 cm de comprimento. Estolão glabro, cilíndrico e ramificado com 1,2 $\mathrm{mm}$ de diâmetro. Ramos assimiladores achatados com 0,3-1,1 cm de largura, sustentado por um curto estipe, medindo 0,4-0,8 $\mathrm{mm}$ de diâmetro. Râmulos falciformes, distribuídos de forma dística, geralmente constritos na base, sobrepostos, margens lisas, recurvados em direção ao ápice, ápice mucronado medindo 1,2-2,2 $\mathrm{mm}$ de largura. Proliferações incomuns, presentes nas porções mediana e apical dos ramos assimiladores foram observadas.

Material examinado: Brasil. Alagoas: Maceió, Praia da Pajuçara - Piscina do Amor, 18-IX-2015, V.A.R. Carneiro 399 \& F.E.G.Q. Lima (MAC58692); Paripueira, Praia de Sonho Verde, 29-IX-2015, V.A.R. Carneiro 182, J.O.F. Brito \& E.A.C. Guedes (MAC58824).
Os espécimes foram coletados nas praias do Pontal do Coruripe, Pajuçara e Sonho Verde. Na praia de Sonho Verde, exemplares com ramos estoloníferos e rizóides mais alongados foram coletados em poças rasas de fundo arenoso e bem iluminados no mediolitoral. Nas demais localidades, os mesmos apresentaram-se semelhantes à forma típica da espécie e foram encontrados essencialmente sobre substrato rochoso em poças e na região protegida do recife, em locais menos expostos à luz e de hidrodinamismo moderado. Alguns exemplares cresciam associados à Caulerpa microphysa e Gelidiella acerosa.

Caulerpa microphysa (Weber Bosse) Feldmann Revue Générale de Botanique 62: 430. 1955. Weber Bosse f. microphysa Weber Bosse, Annales du Jardin Botanique de Buitenzorg 15:361, 362, pl. XXXVIII: fig. 5. 1898. Localidade-tipo: Macassar (Ujung Pandang), Celebes, Indonésia. Basiônimo: Caulerpa racemosa (Forssk.) J.Agardh f. microphysa Weber Bosse

Figura $31, \mathrm{~m}, \mathrm{n}$

Talo de coloração verde clara, formando densos tapetes, de consistência delicada com até $0,9 \mathrm{~cm}$ de altura. Fixos ao substrato através de ramos rizoidais curtíssimos, filamentosos, ramificados, hialinos, com 1-5 mm de comprimento. Estolão glabro, translúcido, cilíndrico, geralmente intricado com 0,1-0,16 mm de diâmetro. Ramos assimiladores curtos, com 5-8 mm de altura, portando de 1-8 râmulos esféricos, de 1-2 mm de diâmetro, sustentado por um curto pedúnculo e distribuído de forma alterna ou irregular.

Material examinado: Brasil. Alagons: Maceió, Praia da Pajuçara - Piscina do Amor, 26-X-2015, V.A.R. Carneiro 118 \& F.E.G.Q. Lima (MAC58723). Praia de Riacho Doce, 4-VIII-2016, J.O.F. Brito 6, V.A.R. Carneiro, E.A.C. Guedes \& M. Fireman (MAC59065). São Miguel dos Milagres, Praia de São Miguel dos Milagres, 29-XII-2015, V.A.R. Carneiro 525 (MAC58937). Paripueira, Praia de Paripueira, 15-VII-2014, V.A.R. Carneiro 59 \& S. Rodrigues (MAC58985).

C. microphysa foi encontrada em todas as estações de coleta. Ocorreu formando densos tapetes sobre substrato rochoso, às vezes recoberto por sedimentos, em áreas de poças, na região protegida do recife e na região frontal do recife, do médio ao infralitoral. Foi frequentemente coletada em áreas sombreadas, com hidrodinamismo moderado a intenso. Na praia do Pontal do Coruripe, alguns exemplares foram 
coletados em fendas do platô recifal. Na praia da Pajuçara, alguns exemplares coletados a 20 metros de profundidade apresentaram os estolões mais esparsos e não formavam tapetes densos. Foram observados que alguns espécimes cresciam associados à Amphiroa anastomosans, Anadyomene stellata (Wulfen) C. Agardh, Caulerpa mexicana, Caulerpa denticulata, Caulerpa verticillata, Gelidiella acerosa, Palisada perforata, Halimeda opuntia, Hypnea spinella e Dictyopteris jamaicensis W.R. Taylor e abrigavam como epífita Griffithsia globulifera Harv. ex Kütz.

Caulerpa prolifera (Forssk.) J.V. Lamour. 1809: 332. Nouveau Bulletin des Sciences, par la Société Philomathique de Paris 1:332. 1809. Fucus prolifer Forsskål, Flora aegyptiaco-arabica: 193. 1775. Localidade-tipo:Alexandria, Egito. Basiônimo:Fucus prolifer Forssk.

Figura $3 \mathrm{k}$

Talo de consistência coriácea, coloração verdeescura com até 10,2 cm de altura. Fixo ao substrato por ramos rizoidais, filamentosos ramificados, de tonalidade amarelada, com 0,5-4,8 cm de comprimento. Estolão glabro a ligeiramente áspero, cilíndrico, ramificado, frequentemente amarelado e às vezes esbranquiçado, com 0,32-2 $\mathrm{mm}$ de diâmetro. Ramos assimiladores achatados, folhosos, geralmente simples, raramente retorcidos, margem lisa e frequentemente amarelados, sustentados por curtos pedúnculos, medindo $0,6-1,1 \mathrm{~cm}$ de largura e 3,5-10 cm de comprimento. Proliferações morfologicamente idênticas aos ramos assimiladores, formando-se, com mais frequência, na região mediana, geralmente em números de 1-2 por ramo assimilador.

Material Examinado: Brasil. AlagoAs: Paripueira, Praia de Sonho Verde, 23-IV-2016, V.A.R. Carneiro 239, J.O.F. Brito, F.E.G.Q. Lima \& E.A.C. Guedes (MAC59307); Praia de Sonho Verde, 29-IX-2015, V.A.R. Carneiro 191, J.O.F. Brito \& E.A.C. Guedes (MAC58819); Coruripe, Praia do Pontal do Coruripe, 24-X-2014, V.A.R. Carneiro 453, J.O.F. Brito, F.E.G.Q. Lima \& E.A.C. Guedes (MAC58885).

Espécie considerada pouco frequente na área de estudo, tendo sido encontrada apenas nas praias de Pontal do Coruripe e Sonho Verde. Em geral, os exemplares foram coletados isoladamente em substratos rochosos e arenosos em poças recifais e topos recifais do médio ao infralitoral, tanto em áreas expostas à luz solar, como em áreas protegidas. $\mathrm{Na}$ praia do Pontal do Coruripe, a espécie foi encontrada em lagunas recifais próximas à região protegida do recife, formando bancos ou associada com Halodule wrighthii e C. denticulata.

Caulerpa racemosa (Forssk.) J.Agardh var. racemosa Till algernes systematik. Nya bidrag. Lunds Universitets Års-Skrift, Afdelningen for Mathematikoch Naturvetenskap 9(8): 1-71.

Figura 4 a, b, c

Talo verde-claro, firme, com até $7,1 \mathrm{~cm}$ de altura. Fixo ao substrato por ramos rizoidais cilíndricos, densamente ramificados, translúcidos ou amarelados, com 0,2-0,9 cm de comprimento. Estolão cilíndrico, glabro e ramificado. Ramos assimiladores cilíndricos, com 2,7-5,4 cm de altura e 0,7-10,2 mm de largura. Râmulos sustentados por pedúnculos curtos, ápice globoso, dispostos radialmente no ramo assimilador, com 0,6-8 mm de comprimento e 0,5-1,2 $\mathrm{mm}$ de diâmetro.

Material examinado: Brasil. Alagoas. Maceió: Praia da Pajuçara, 18-IX-1986, M.J.B. Mendes 671, I. Moreira \& A. Pinheiro (MAC59280); Praia da Pajuçara, 13-VI-2014, V.A.R. Carneiro 88, M.F.O. Carvalho \& S. Rodrigues (MAC58953); Marechal Deodoro: Praia do Francês, 21-XI-1987, M.J.B. Mendes 457, A.D.J. Matos \& J.J. Santos (MAC5579); Praia do Francês, 25-VIII-1987, M.J.B. Mendes 398, \& J.E. Nascimento (MAC5521); Praia do Saco de Pedra, 7-VIII-1987, M.J.B. Mendes 531, J.S. Moreira, A.I.L. Pinheiro \& I. Mouly (MAC5593); Piaçabuçu: Praia do Pontal do Peba, 13-VIII-2007, M.J.F. Silva s/n, E.A.C. Guedes \& L.M.V. Nova (MAC59123); Paripueira: Praia de Sonho Verde, 29-IX-2015, V.A.R. Carneiro 183, J.O.F. Brito \& E.A.C. Guedes (MAC58829); São Miguel dos Milagres: Praia de São Miguel dos Milagres, 4-VII-2007, M.J.F. Silva s/n, E.A.C. Guedes \& L.M.V. Nova (MAC59122).

Os espécimes foram encontrados em todas as praias, sendo considerada muito comum na área de estudo. A espécie foi coletada com mais frequência em substratos rochosos de topos recifais, poças, na região protegida do recife e na região frontal do recife, em locais emersos e expostos à insolação durante a maré baixa, frequentemente formando densas populações.

Caulerpa sertularioides (S.G.Gmel.) M.Howe Bulletim of the Torrey Botanical Club 32: 576. 1905. Localidade-tipo: "incoralliis americanis". Basiônimo: Fucus sertularioides S.G. Gmel., Historia fucorum: 151. 1768.

Figura $4 \mathrm{~d}, \mathrm{e}, \mathrm{f}$ 

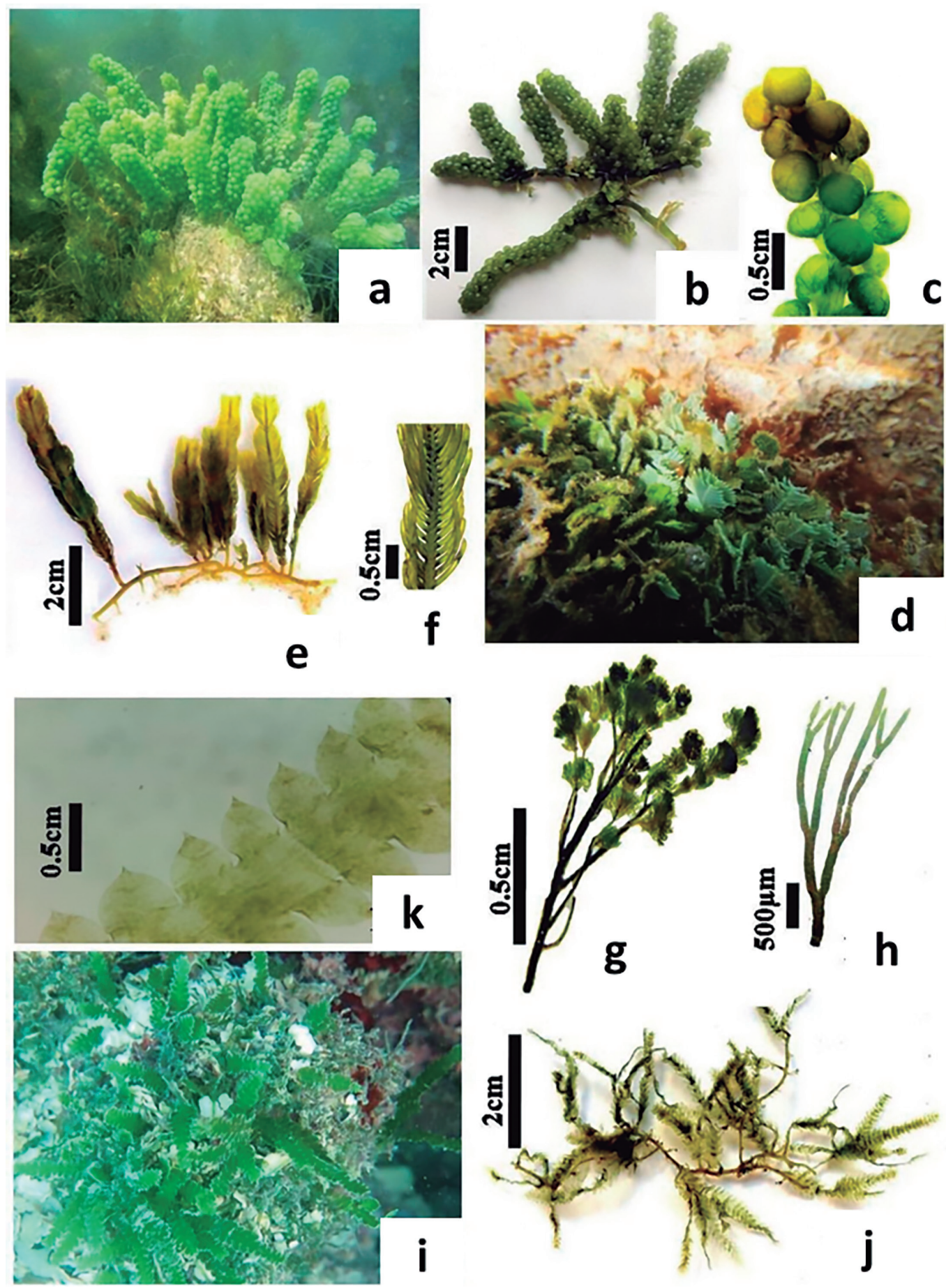

Figura 4. Caulerpa racemosa var. racemosa. a. Hábito do talo em ambiente natural. b. Hábito geral do talo. c. Detalhe de parte de um ramo assimilador portando râmulos curtos e globóides. Caulerpa sertularioides. d. Hábito do talo em ambiente natural. e. Hábito geral do talo. f. Detalhe de parte de um ramo assimilador portando pínulas dispostas disticamente. Caulerpa verticillata. g. Detalhe de parte de um ramo assimilador portando verticilos filamentosos. h. Detalhe de um râmulo do verticilo, sem constrição na base e ramificações dicotômicas. Caulerpa sp. i. Hábito do talo em ambiente natural. j. Hábito geral do talo. k. Detalhe de parte de um ramo assimilador com râmulos achatados, nunca sobrepostos, com ápice mucronado.

Figure 4. Caulerpa racemosa var. racemosa. a. Habit in natural environment. b. Habit of the thallus. c. Detail of assimilator branch showing short and spherical branchlets. Caulerpa sertularioides. d. Habit in natural environment. e. Habit of the thallus. f. Detail of assimilator branch with disthic pinnae. Caulerpa verticillata. g. Detail of assimilator branch showing filamentous whorls. h. Detalhe of whorl branchlet. Caulerpa sp. i. Habit in natural environment. j. Habit of the thallus. k. Detail of assimilator branch with flatted branchlets, never overlapped, with mucronate apex. 
Talo verde-claro, firme, com até $8,5 \mathrm{~cm}$ de altura. Fixo ao substrato por ramos rizoidais ramificados, geralmente hialinos, raramente amarelados com 0,4-2,7 cm de comprimento. Estolão glabro, cilíndrico, pouco ramificado, com 0,8-2 mm de diâmetro. Ramos assimiladores cilíndricos, geralmente simples, às vezes ramificados, pedunculados ou sésseis, com 1,5-8,3 cm de altura e 3,5-12,2 $\mathrm{cm}$ de largura. Râmulos cilíndricos, sem constrição na base, dispostos disticamente conferindo um aspecto penado à fronde ou tendendo a recobrir parcialmente o eixo central do ramo assimilador, leve ou fortemente curvados em direção ao ápice, com ápice mucronado com 1-6 mm de comprimento e 0,45-0,6 mm de diâmetro.

Material examinado: Brasil. AlagoAs: Maceió, Praia da Garça Torta, 25-III-1986, M.J.B. Mendes 28, A.I.L.Pinheiro, I.S. Moreira \& U. Omena (MAC5071). Praia de Ipioca, 4-XI-1986, M.J.B. Mendes 227, J.E. Nascimento \& U. Omena (MAC5200). Praia da Pajuçara, 18-IX-1986, M.J.B. Mendes 330, A.I.L. Pinheiro \& I.S. Moreira (MAC5089). Praia da Ponta Verde, 25-V-1986, M.J.B. Mendes 654, A.I.L. Pinheiro \& I.S. Moreira (MAC5660). Praia de Riacho Doce, 4-VIII-2016, J.O.F. Brito 18, V.A.R. Carneiro, M. Fireman \& E.A.C. Guedes (MAC59062). São Miguel dos Milagres, Praia de São Miguel dos Milagres, 4-VII-2007, M.J.F. Silva, E.A.C. Guedes \& L.L.M.V. Nova s/n (MAC59121).

Espécie comum na área de estudo, tendo sido encontrada em todas as praias estudadas. A maioria dos espécimes foi coletada em poças, na região protegida do recife e lagunas recifais do médio ao infralitoral. Na praia de Riacho Doce, a espécie foi encontrada formando pequenos bancos sobre o substrato rochoso de topos recifais baixos, recoberto por sedimento. Alguns exemplares também foram encontrados em poças sobre fundo arenoso, crescendo de forma isolada sem formar bancos. Alguns exemplares cresciam associados à Halimeda opuntia, Gelidium crinale, $C$. denticulata e Palisada perforata e abrigavam como epífitas Hypnea pseudomusciformis e Dictyopteris delicatula.

Caulerpa verticillata J. Agardh Agardh, J.G. (1847). Nya alger från Mexico.Öfversigt af Kong1. Vetenskaps-Adademiens Förhandlingar, Stockholm 4:5-17. Localidade-tipo: Nãoespecificada [Índias Ocidentais fide J. Agardh 1873:7].

Figura $4 \mathrm{~g}, \mathrm{~h}$
Talo verde-escuro, firme, com até $1,5 \mathrm{~cm}$ de altura. Fixo ao substrato por ramos rizoidais ramificados, com 0,12-0,2 cm de comprimento. Estolão glabro, cilíndrico e ramificado com 0,3-0,9 $\mathrm{mm}$ de diâmetro. Ramos assimiladores cilíndricos, simples ou ramificados, portando sequências de 1-4 tufos de verticilos filamentosos, ligeiramente sobrepostos com 2,8-5,6 $\mathrm{mm}$ de largura e 3,2-15 $\mathrm{mm}$ de altura. Cada verticilo é formado por râmulos dispostos radialmente, não recurvados em direção ao ápice, ramificados dicotomicamente até $3^{\mathrm{a}}$ ordem, sem constrição na base. Ápices dos râmulos arredondados ou apresentando de 1-2 múcrons.

Material examinado: Brasil. Alagoas. Maceió, Praia da Pajuçara - Piscina do Amor, 18-IX-2015, V.A.R.Carneiro 9 \& F.E.G.Q.Lima (MAC58731). São Miguel dos Milagres, Praia de São Miguel dos Milagres, 29-XII-2015, V.A.R. Carneiro 435 (MAC58934).

Esta espécie foi coletada nas praias de São Miguel dos Milagres e Pajuçara, crescendo sobre substrato rochoso de poças e topos recifais do infralitoral, em locais expostos à luz ou sombreados. Alguns exemplares cresciam associados à Caulerpa microphysa e Amphiroa sp.

\section{Caulerpa sp.}

Figura i, j, k

Talo verde-claro, delicado, com até 4,6 cm de altura. Fixo ao substrato por ramos rizoidais ramificados, de tonalidade amarelada a translúcida, com 0,12-0,2 cm de comprimento. Estolão glabro, cilíndrico, de tonalidade amarelada ou esverdeada, com $0,8 \mathrm{~mm}$ de diâmetro. Ramos assimiladores achatados, simples ou di-tricotômicos, com 1-8-4,5 cm de comprimento e 0,3-1 cm de largura. Eixo central do ramo assimilador achatado, com 0,1-1 cm de largura. Râmulos achatados, sésseis, nunca sobrepostos, de margem lisa, levemente recurvados em direção ao ápice ou quase retos, apresentando ápice mucronado.

Material examinado: Brasil. AlagoAs: Maceió, Praia da Pajuçara, Piscina do Amor, 19-V-2015, F.E.G.Q. Lima 10 (MAC59027).

Espécime único coletado no infralitoral da praia da Pajuçara numa área recifal conhecida como "Piscina do Amor". Foi encontrado em poças recifais de áreas protegidas, crescendo em substrato rochoso, em área sombreada com baixo hidrodinamismo, associado a C. microphysa. As dimensões gerais do 
talo e o padrão de ramificação dos râmulos levam a crer que o espécime em questão se trate de uma variedade de C. mexicana Sond. ex Kütz. No entanto, outras características morfológicas põem em dúvida sua correspondência com C. mexicana, uma vez que apresenta râmulos sésseis, ovalados e raramente sobrepostos. Dessa forma, preferiu-se deixar ao nível de espécie não identificada, tendo em vista que o referido trabalho não contempla dados moleculares para um suporte mais preciso.

Distribuição de Caulerpa no litoral do Estado de Alagoas - Com base no material coletado e nas exsicatas depositadas no Herbário MAC, verificouse a ocorrência do gênero Caulerpa em 17 praias ao longo do litoral de Alagoas (tabela 2). Dentre os táxons analisados, C. chemnitzia, C. cupressoides, Caulerpa cupressoides var. lycopodium e C. sertularioides apresentaram uma ampla distribuição geográfica no referido litoral. Ainda de acordo com a tabela 2, com relação às praias coletadas, os maiores registros foram verificados para Pajuçara (11), Sonho Verde (10), Riacho Doce (9) e Pontal do Coruripe (8).

Ao comparar a diversidade do gênero Caulerpa do presente estudo com os demais Estados do Nordeste, baseados nos trabalhos de Barata et al. (2008), Brayner et al. (2008) e Moura 2015, a saber: Bahia (23 sp.), Pernambuco (20 sp.), Paraíba (17 sp.), Rio Grande do Norte (17 sp.), Ceará (15 sp.), Piauí (seis sp.), Maranhão (duas sp.) e Sergipe (uma sp.), pode-se afirmar que o litoral do Estado de Alagoas encontrou-se bem representado, com 12 espécies e três variedades. Salienta-se que por motivo de logística, outras praias não foram contempladas no presente estudo, como por exemplos, a praia do Saco, a praia do Patacho, a praia do Carneiro, entre outras. Acredita-se que com um estudo mais abrangente e direcionado principalmente para a região de infralitoral, essa diversidade para o gênero seja ampliada nesse litoral.

Em relação ao tipo de substrato (tabela 3), a maioria dos táxons ocorreu concomitantemente em substratos rochosos e arenosos, tendo essa caracterização similar à que foi observada por Brayner et al. (2008), por meio da análise do material pernambucano. A partir da comparação morfométrica entre as dimensões gerais dos eixos e filamentos rizoidais em indivíduos de C. cupressoides, C. cupressoides var. flabellata, C. cupressoides var. lycopodium, C. mexicana e $C$. denticulata, coletados tanto em substrato arenoso como rochoso, foi possível constatar que essas estruturas possuíam dimensões bem maiores em exemplares coletados em substrato arenoso. Estolões densamente intricados foram observados em exemplares de $C$. chemnitzia, $C$. denticulata, $C$. microphysa, C. fastigiata e $C$. verticillata coletados em áreas com condições hidrodinâmicas regularmente variáveis. Também foi possível observar em alguns exemplares coletados em substrato arenoso de $C$. cupressoides e C. denticulata que, em dois ou mais ramos rizoidais distintos, ligeiramente afastados entre si, possuíam seus filamentos rizoidais unidos. No entanto, não foi verificada a presença de anastomoses verdadeiras. Ramos rizoidais abundantes e rizóides mais ramificados foram observados em indivíduos coletados em substrato rochoso, especialmente em $C$. chemnitzia e C. racemosa. Acredita-se que todas as variações morfométricas dessas estruturas analisadas no material alagoano, embora não tenham relevância taxonômica, podem indicar uma adaptação ao tipo de substrato. $C$. prolifera e $C$. cupressoides var. lycopodium foram coletadas apenas em locais onde a incidência luminosa é mais direta, como em poças e topos recifais.

Quanto aos microambientes recifais (tabela 3), os táxons do gênero Caulerpa ocorreram principalmente em poças recifais, em topos recifais e na região protegida do recife. A maioria dos táxons foi encontrada tanto em locais expostos quanto submersos, o que pode demonstrar que os mesmos possivelmente estejam bem adaptados às oscilações das marés no mediolitoral, local onde foram encontrados em maior número. No entanto, diferentemente da maioria dos táxons analisados neste estudo, algumas espécies parecem não tolerar áreas expostas durante a maré baixa, como $C$. kempfii e $C$. verticillata, tendo sido coletadas apenas no infralitoral.

Comparando os dados obtidos na presente pesquisa com os de Muniz (1993) e Lemos et al. (2017), foram confirmadas as ocorrências de $C$. chemnitzia (citada como C. racemosa var. laetevirens); C. cupressoides, C. cupressoides var. lycopodium, $C$. denticulada (citada como C. scalpelliformis var. denticulata), C. fastigiata, C. prolifera, C. racemosa var. racemosa e $C$. sertularioides para o litoral do Estado de Alagoas. Contudo, C. lanuginosa J. Agardh e C. pusilla var. mucronata não foram registradas na presente pesquisa, tendo em vista que, as coletas do presente estudo foram direcionadas principalmente para os representantes da região entremarés. Em geral, esses táxons são frequentemente registrados em flora de infralitoral em outras localidades do Nordeste (Pereira 1974, Oliveira-Carvalho et al. 2003, Barata 
Tabela 2. Distribuição de ocorrência de Caulerpa ao longo do litoral do Estado de Alagoa com base em coletas recentes realizadas pela presente pesquisa e exsicatas analisadas no Herbário MAC.

Table 2. Caulerpa distribution along Alagoas State coast. Data obtained in this study and from Herbário MAC deposited vouchers.

\section{Praias do litoral de Alagoas}

Táxons

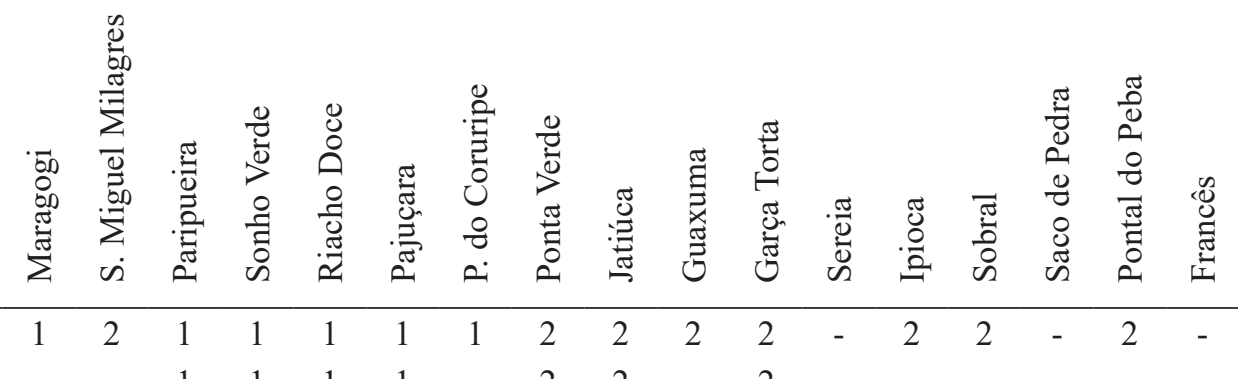

\section{C. chemnitzia}

C. cupressoides

C. cupressoides var. flabellata

C. cupressoides var. lycopodium

C. denticulata

C. fastigiata

C. kempfii

C. mexicana

C. microphysa

C. prolifera

C. racemosa var. racemosa

C. sertularioides

C. verticillata

Caulerpa sp

1: Material coletado, 2: Exsicata Herbário MAC, -: Ausência

Tabela 3. Distribuição de ocorrência de Caulerpa nos diferentes tipos de substratos (rochoso e arenoso) e microambientes (RFR: Região Frontal do Recife, PL: Platô Recifal, Pçs: Poças de Maré, TP: Topo Recifal, RPR: Região Protegida do Recife, LR: Laguna Recifal) ao longo do litoral do Estado de Alagoas.

Table 3. Caulerpa distribution along Alagoas State coast, considering the substrate (rochy and sandy) and microhabitats (RFR: Região Frontal do Recife, PL: Platô Recifal, Pçs: Poças de Maré, TP: Topo Recifal, RPR: Região Protegida do Recife, LR: Laguna Recifal).

\begin{tabular}{|c|c|c|c|c|c|c|c|c|}
\hline \multirow[b]{2}{*}{ Táxons } & \multicolumn{2}{|c|}{ Substratos } & \multicolumn{6}{|c|}{ Microambientes } \\
\hline & $\begin{array}{l}0 \\
\& \\
0 \\
\frac{0}{0} \\
0 \\
0\end{array}$ & 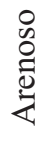 & $\stackrel{\mathscr{b}}{a}$ & $\frac{\alpha}{\alpha}$ & $\tilde{u}$ & $\stackrel{\mathscr{f}}{\theta}$ & $\overrightarrow{2}$ & $\frac{\alpha}{\alpha}$ \\
\hline Caulerpa chemnitzia & $\mathrm{X}$ & - & - & $\mathrm{X}$ & $\mathrm{X}$ & $\mathrm{X}$ & - & $\mathrm{X}$ \\
\hline C. cupressoides & $\mathrm{X}$ & $\mathrm{X}$ & $\mathrm{X}$ & - & $\mathrm{X}$ & $\mathrm{X}$ & - & - \\
\hline C. cupressoides var. flabellata & $\mathrm{X}$ & $X$ & - & - & $\mathrm{X}$ & - & - & $\mathrm{X}$ \\
\hline
\end{tabular}


Tabela 3 (continuação)

\begin{tabular}{|c|c|c|c|c|c|c|c|c|}
\hline \multirow[b]{2}{*}{ Táxons } & \multicolumn{2}{|c|}{ Substratos } & \multicolumn{6}{|c|}{ Microambientes } \\
\hline & 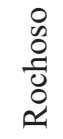 & 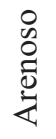 & $\stackrel{\simeq}{\exists}$ & $\frac{\underline{a}}{a}$ & $2^{2}$ & $\stackrel{\underline{r}}{\mathscr{F}}$ & $\vec{a}$ & $\frac{\underline{x}}{\underline{x}}$ \\
\hline C. cupressoides var. lycopodium & $\mathrm{X}$ & $\mathrm{X}$ & - & - & $\mathrm{X}$ & $\mathrm{X}$ & - & - \\
\hline C. denticulata & $\mathrm{X}$ & $\mathrm{X}$ & $\mathrm{X}$ & $\mathrm{X}$ & $\mathrm{X}$ & $\mathrm{X}$ & $\mathrm{X}$ & - \\
\hline C. fastigiata & $\mathrm{X}$ & $\mathrm{X}$ & - & $\mathrm{X}$ & $X$ & - & - & - \\
\hline C. kempfii & $\mathrm{X}$ & $\mathrm{X}$ & - & - & - & $\mathrm{X}$ & - & - \\
\hline C. mexicana & $\mathrm{X}$ & $\mathrm{X}$ & - & $\mathrm{X}$ & $\mathrm{X}$ & $\mathrm{X}$ & - & - \\
\hline C. microphysa & $\mathrm{X}$ & - & - & $\mathrm{X}$ & $\mathrm{X}$ & - & $\mathrm{X}$ & $\mathrm{X}$ \\
\hline C. prolifera & $\mathrm{X}$ & $\mathrm{X}$ & $\mathrm{X}$ & $\mathrm{X}$ & $\mathrm{X}$ & - & - & - \\
\hline C. racemosa var. racemosa & $\mathrm{X}$ & - & - & $\mathrm{X}$ & $\mathrm{X}$ & $\mathrm{X}$ & - & $\mathrm{X}$ \\
\hline C. sertularioides & $\mathrm{X}$ & $\mathrm{X}$ & $\mathrm{X}$ & $\mathrm{X}$ & $X$ & $\mathrm{X}$ & - & - \\
\hline C. verticillata & $X$ & - & - & - & $X$ & $X$ & - & - \\
\hline Caulerpa sp & $\mathrm{X}$ & - & - & $\mathrm{X}$ & $\mathrm{X}$ & - & - & - \\
\hline
\end{tabular}

Presente (x) ausente (-)

2008, Brayner et al. 2008). Na presente pesquisa, foram registradas seis novas ocorrências para o litoral de Alagoas, a saber, C. cupressoides var. fabelata, $C$. kempfii, C. mexicana, C. microphysa, C. verticillata e Caulerpa sp, ampliando desta forma, a distribuição geográfica no Nordeste brasileiro.

\section{Agradecimentos}

Os autores agradecem ao Instituto do Meio Ambiente de Alagoas (IMA), pela concessão de bolsa ao primeiro autor, à equipe do Herbário MAC por todo o suporte nas análises das exsicatas e à equipe do gerenciamento costeiro do IMA (GERCO) pelo apoio logístico nas coletas na enseada da Pajuçara e na última coleta em Maragogi.

\section{Literatura citada}

Barata, D. 2008. Taxonomia e filogenia do gênero Caulerpa J.V.Lamour. (Bryopsidales, Chlorophyta) do Brasil. Tese de Doutorado, Instituto de Botânica da Secretaria de Estado do Meio Ambiente, São Paulo.

Belton, G.S., van Reine, W.F.P.H., Huisman, J.M., Draisma, S.G., \& D. Gurgel, C.F. 2014. Resolving phenotypic plasticity and species designation in the morphologically challenging Caulerpa racemosapeltata complex (Chlorophyta, Caulerpaceae). Journal of Phycology 50:1, 32-54.
Brayner, S., Pereira, S.M.B. \& Bandeira-Pedrosa, M.E. 2008. Taxonomy and distribution of the genus Caulerpa Lamouroux (Bryopsidales-Chlorophyta) on the coast of Pernambuco State and Fernando de Noronha Archipelago, Brazil. Acta Botanica Brasilica 22: 914-928.

Bulleri, F., Balata, D., Bertocci, I., Tamburello, L., \& Benedetti-Cecchi, L. 2010. The seaweed Caulerpa racemosa on Mediterranean rocky reefs: from passenger to driver of ecological change. Ecology 91: 2205-2212.

Car, A., Witkowski, A., Jasprica, N., Ljubimir, S., Čalić, M., Dobosz, S., Radić, I.\& Hrustić, E. 2019. Epilithic diatom communities from areas of invasive Caulerpa species (Caulerpa taxifolia and Caulerpa cylindracea) in the Adriatic Sea, NE Mediterranean. Mediterranean Marine Science 20: 151-173.

Coppejans, E., \& Beeckman, T. 1990. Caulerpa (Chlorophyta, Caulerpaceae) from the Kenya coast. Nova Hedwigia 50: 111-125.

Correia, M.D., \& Sovierzoski, H.H. 2005. Ecossistemas Marinhos: recifes, praias e manguezais. Edufal.

Draisma, S.G.A., van Reine, W.F.P., Sauvage, T., Belton, G.S., Gurgel, C.F.D., Lim, P.-E. \& Phang, S.-M. 2014. A re-assessment of the infra-generic classification of the genus Caulerpa (Caulerpaceae, Chlorophyta) inferred from a time-calibrated molecular phylogeny. Journal of Phycology 50: 1020-1034.

Ertan, O.O., Turna, I.I. \& Cormaci, M. 1998. A New Record for the Marine Algal Flora of Turkey: Caulerpa scalpelliformis (Brown ex Turner) C. Agardh (Caulerpaceae, Chlorophyceae). Turkish Journal of Botany 22: 285-287. 
Famà, P., Wysor, B., Kooistra, W.H.C.F. \& Zuccarello, G.C. 2002. Molecular phylogeny of the genus Caulerpa (Caulerpales, Chlorophyta) inferred from chloroplast tufA gene. Journal of Phycology 38: 1040-1050.

Ferreira, M.M. \& Pinheiro, F.C. 1966. Primeira contribuição ao inventário das algas marinhas bentônicas do Nordeste brasileiro. Arquivo da Estação de Biologia Marinha da Universidade Federal do Ceará. Ceará. Ceará, v. 6, n. 1, pp. 59-66.

Fidalgo, O. \& Bononi, V.L. 1984. Técnicas de coleta, preservação e herborização de material botânico. Instituto de Botânica, São Paulo.

Guiry, M.D. \& Guiry, G.M. 2019. AlgaeBase. World-wide electronic publication, National University of Ireland, Galway. Disponível em http://www.algaebase.org (acesso em 23-VIII-2018).

Horta, P.A., Amancio, E., Coimbra, C.S. \& Oliveira, E.C. 2001. Considerações sobre a distribuição e origem da flora de macroalgas marinhas brasileiras. Hoehnea 28: 243-265.

Jousson, O., Pawlowski, J., Zaninetti, L., Meinesz, A. \& Boudouresque, C.F. 1998. Molecular evidence for the aquarium origin of the green alga Caulerpa taxifolia introduced to the Mediterranean Sea. Marine Ecology Progress Series 172: 275-280.

Lemos, R.P.L, V.A.R.Carneiro, Costa, M.M.S. \& Guedes, E.A.C. 2017. Macroalgas marinhas do Estado de Alagoas: Coleção Histórica e Perspectivas. Revista Ambiental do Instituto do Meio Ambiente do Estado de Alagoas, 1: 122-139.

Meinesz, A., Belsher, T., Thibaut, T., Antolic, B., Mistapha, K.B., Boudouresque, C.F., Chiaverini, D., Cinelli, F., Cottalorda, J.M., Djellouli, A., Abed, A.E., Orestano, C., Grau, A.M., Ivesa, L., Jaklin, A., Langar, H., MassutiPascual, E., Peirano, A., Tunesi, L., Vaugelas, J., Zavodnik, N. \& Zuljevic, A. 2001. The introduced green alga Caulerpa taxifolia continues to spread in the Mediterranean. Biological Invasions 3: 201-210.

Moura, C.W.N. 2015. Caulerpa in Lista de Espécies da Flora do Brasil. Jardim Botânico do Rio de Janeiro. Disponivel em http://floradobrasil.jbrj.gov.br/jabot/ floradobrasil/FB99052 (acesso em 11-VII-2018).

Muniz, J.A.1993. Enumeração e novas ocorrências de algas marinhas bentônicas para o Estado de Alagoas, Brasil. Revista Nordestina de Biologia 81: 1-4.

Nunes, J.M.C, \& Paula, E.J. 2002. Composição e distribuição das Phaeophyta nos recifes da região metropolitana de Salvador, Bahia, Brasil. Iheringia, série botânica 57: 113-130.
Oliveira-Carvalho, M.F., Pereira, S.M.B. \& Zickel, C.S. 2003. Florística e distribuição espaço-temporal das clorofíceas bentônicas em trechos recifais do litoral norte do Estado de Pernambuco - Brasil. Hoehnea 30: 112-201.

Padilha, R.J.A. 2014. Perfil químico e atividade antimicrobriana de Caulerpa racemosa (Forsskal) J. Agardh. Dissertação de Mestrado, Universidade Federal de Pernambuco, Recife.

Pereira, S.M.B. 1974. Clorofíceas marinhas da Ilha de Itamaracá e arredores (Estado de Pernambuco - Brasil). 184p. Dissertação de Mestrado, Universidade de São Paulo. São Paulo.

Santos, R.C.A.L. 2004. Evolução da linha da Costa a Médio e Curto prazo associada ao grau de desenvolvimento urbano e aos aspectos geoambientais na planície costeira de Maceió-AL. Tese de Doutorado. Instituto Oceanográfico da Universidade de Pernambuco. Recife.

Silva, P.C. 2003. Historical overview of the genus Caulerpa. Cryptogamie, Algologie 24:33-50.

Souza, E.T.2011. Evaluation of the potencial antinociceptive and anti-inflammatory of the benthic alga Caulerpa racemosa (Forssk.) J.Agardh (Caulerpaceae). Dissertação de Mestrado, Universidade Federal de Alagoas, Maceió.

Taylor, W.M.R. 1960. Marine algae of the eastern tropical and subtropical coast of the Americas. Ann. Arbor. The University of Michigan Press.

Trono, JR., G.C. 1999. Diversity of the seaweed flora of the Philipines and its utilization. Hidrobiologia 398/399:1-6.

Verlaque, M., Durand, C., Huisman, J.M., Boudouresque, C.F., Le Parco, Y. 2003. On the identity and origin of the Mediterranean invasive Caulerpa racemosa (Caulerpales, Chlorophyta). European Journal of Phycology 38: 325-339.

Wynne, M.J. 2017. A checklist of benthic marine algae of the tropical and subtropical western Atlantic: fourth revision. Nova Hedwigia, Beihefte, Beih.

Yeh, W., Chen, G. 2004. Nuclear rDNA and internal transcribed spacer sequences clarify Caulerpa racemosa vars. from other Caulerpa species. Aquatic Botany 80: 193-207.

Zaleski, S.F. \& Murray, S.T. 2006. Taxonomic diversity and geographic distributions of aquarium $=$ traded species of Caulerpa (Chlorophyta: Caulerpaceae) in southern California, USA. Marine Ecology Progress Series 314: 97-10. 